\title{
38. Loss of Phototactic Behavior in Silkworm Larvae Reared on Synthetic Diet
}

\author{
By Isamu Shimizu, Seiji Kitabatake, and Masaru Kato \\ Laboratory for Plant Ecological Studies, Faculty of Science, \\ Kyoto University \\ (Comm. by Kiyoshi Takewaki, M. J. A., March 12, 1976)
}

It is well known that environmental conditions affect the growth, voltinism, behavior and other characters of the silkworm, Bombyx mori. Recently it has been reported that synthetic diets altered some of these characters. ${ }^{1), 2)}$ The present studies show that a synthetic diet, which is sufficient to rear silkworms, induces a loss of phototactic behavior in silkworm larvae.

Material and methods. A bivoltine race of the silkworm, Bombyx mori ( $\mathrm{F}_{1}$ of the cross between the races Gunka and Hoshun) was used as experimental material. This strain shows a strong positive phototactic response to yellow and ultraviolet radiations. A slide projector was used for estimation of phototactic response of silkworm larvae. Monochromatic light $(\lambda \max =585 \mathrm{~nm})$ obtained by means of an interference filter was projected on a sheet of white paper fixed in the bottom of a black box. The light intensity on the paper was adjusted to $1.7 \times 10^{-1} \mathrm{watt} / \mathrm{cm}^{2}$. Dark-adapted larvae were placed on the starting area in the black box. Larvae showing positive phototactic behavior rapidly oriented toward and moved to the lighted area. Larvae reaching the paper within $10 \mathrm{~min}$ were counted, and the percentage of these larvae was used as an index of the phototactic activity. Semi-synthetic diet (M-0) was prepared according to the method of Kato. ${ }^{1)}$ It is mainly composed of soybean protein and cellulose containing neither mulberry leaf powder nor its extracts. Another diet (M-101) largely consisting of mulberry leaf powder and chlorella powder was also prepared.

Results and discussion. It has already been reported that both newly hatched and matured larvae of the silkworm, Bombyx mori, show marked phototactic responses. ${ }^{3)}$ In the first experiment, it was demonstrated that newly hatched and molted larvae usually moved toward the lighted area but they became unresponsive after feeding and temporary starvation was followed by its recovery. Fig. 1 shows the phototactic activities of newly hatched, molted and matured larvae. Fifty newly molted larvae at every instar kept starved for $8 \mathrm{hr}$ were used in each phototactic assay. Larvae fed mulberry leaves (ML) 


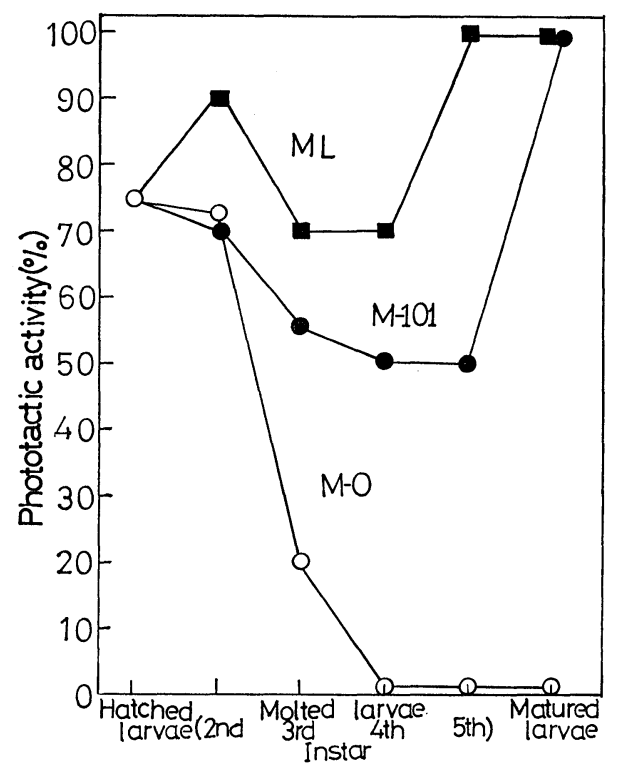

Fig. 1. Phototactic responses in larvae reared on $\mathrm{M}-0$, M-101 and ML. M-0, semi-synthetic diet without mulberry leaf powder or its extracts; M-101, prepared diet containing mulberry leaf powder; $\mathrm{ML}$, mulberry leaves.

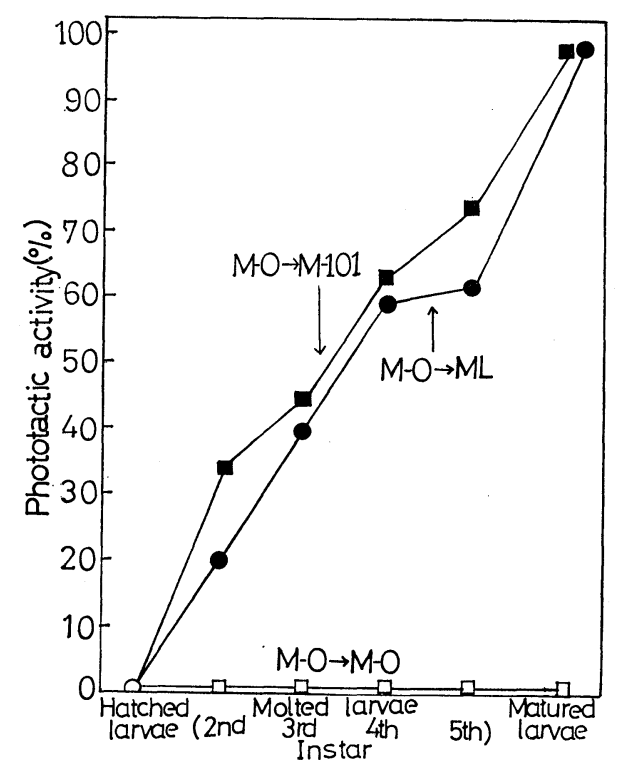

Fig. 2. Recovery of phototactic responses of offspring larvae hatched from eggs laid by female moths from larvae reared on M-0 diet. 
or M-101 diet exhibited phototactic responses throughout larval stages. The responses of matured larvae were most marked. The apparent fall of the activities in the 3rd and 4th instar larvae on ML, the 3rd-5th instar larvae on M-101 might be due to an inadequacy of starvation effect. On the contrary, the phototactic activities of larvae on M-0 diet were gradually lowered as the larvae grew, until finally lost completely in the 4 th and 5th instars. It is interesting to note that, although matured larvae kept on this diet did not show any phototactic response to yellow, ultraviolet and white radiations, they exhibited positive geotaxis normally. It was found in our preliminary experiments that an addition of chloroform extracts of mulberry leaf powder to the M-0 diet recovered phototactic behavior in matured larvae. This suggests that lipophilic compounds in mulberry leaves are necessary to develop the larval phototactic responses.

In the second experiment, it was found that not only old and matured larvae reared on M-0 diet but also newly hatched offspring larvae of the silkworms fed on this same diet failed to show phototactic behavior. These larvae were physically active, moving around in the black box soon after hatching. Their chemotactic responses were apparently normal. A preliminary experiment demonstrated that the addition of chloroform extracts of mulberry leaf powder to M-0 diet was highly effective in recovering phototactic behavior in these newly hatched as well as matured larvae. If they were reared on mulberry leaves or M-101 diet from the beginning, the phototactic activities were recovered gradually (Fig. 2).

In the third experiment, hybridization analyses were carried out between silkworms reared on M-101 diet and M-0 diet (Table I). Newly hatched larvae from eggs laid by female moths reared on M-101 diet showed positive phototaxis, males playing no part in the responses. These results suggest that the compound indispensable to the development of phototactic response of larvae is transferred

Table I. Hybridization analyses of phototactic behavior of larvae newly hatched from eggs laid by silkworms reared on M-0 and M-101 diets

\begin{tabular}{lcc}
\hline & $\begin{array}{c}\text { Phototactic } \\
\text { activities }\end{array}$ & $\begin{array}{c}\text { *Positive } \\
\text { orientation }\end{array}$ \\
\hline $\mathrm{M}-0$ 우 $\times \mathrm{M}-0$ 个 & $0 \%$ & $34 \%$ \\
$\mathrm{M}-0$ 우 $\times \mathrm{M}-101$ 令 & 0 & 52 \\
$\mathrm{M}-101$ 우 $\times \mathrm{M}-0$ 오 & 65 & 95 \\
$\mathrm{M}-101$ 우 $\times \mathrm{M}-101$ 合 & 62 & 97 \\
\hline
\end{tabular}

Each value is mean of four experiments.

* The percentage of larvae orienting to yellow radiation. 
into embryos from the maternal blood. It seems to be interesting to see that food conditions affect the behavior of the next generation.

Investigation on the nature of compounds involved and mechanism concerning the loss of phototactic responses in silkworm larvae are under way.

Acknowledgements. The authors are grateful to Dr. H. Yamada for his kind advices. This work was supported by a Scientific Research Grant from the Ministry of Education of Japan.

\section{References}

1) Kato, M.: On the chemical and physical environmental factors for embryonic diapause in silkworm Bombyx mori fed on artificial diet. Environ. Control in Biol., 12, 1 (1974).

2) —_: Light and temperature compensate possibly for chemical conditions of embryonic development in the silkworm Bombyx mori. Proc. Japan Acad., 49, 205 (1973).

3) Yagi, N.: Cocoon colour and phototaxis of silkworm. Zoological Magazine, 35, 71 (1923). 